\title{
Evaluation of the susceptibility to pigmentation of orthodontic esthetic elastomeric ligatures
}

\author{
Janine Soares Cavalcante1, Marcelo de Castellucci e Barbosa², Marcio Costa Sobral²
}

\begin{abstract}
Objective: The purpose of this laboratory study was to evaluate changes in the pigmentation of esthetic elastomeric ligatures after immersion in a staining solution. Methods: Sixty ligatures were selected and divided into 12 groups according to their brand and also considering their condition, i.e., unstretched or stretched. The groups were divided into: Morelli (clear), TP Orthodontics (clear), American Orthodontics (clear), 3M/Unitek (clear), American Orthodontics (pearl color) and 3M/Unitek (pearl color), separated into groups of 5 unstretched and five stretched ligatures. Assessment of their color changes was performed by means of digital photograph and computer analysis using Adobe Photoshop. Standardized digital photographs were taken at $\mathrm{T}_{0}$ (before the staining process, with unstretched ligatures) and at $\mathrm{T}_{1}$ (following the 5 -days staining process). The staining solution was composed of artificial saliva and foods with staining potential. At $T_{1}$ the ligatures were either stretched or unstretched. Results: The results of this study showed that esthetic elastomeric ligatures are prone to staining. Among the evaluated brands, TP Orthodontics and American Orthodontics clear ligatures were the most stable. Moreover, 3M/Unitek pearl ligatures demonstrated statistically significant changes in all variables. Conclusions: Esthetic elastomeric ligatures are susceptible to staining and no statistically significant difference was found between unstretched or stretched ligatures, with the sole exception of the TP Orthodontics brand. The 3M/Unitek's pearl color ligatures displayed the greatest staining potential.
\end{abstract}

Keywords: Esthetics. Staining. Photography. Ligature.

Objetivo: avaliar alterações da pigmentação de ligaduras elásticas estéticas após imersão em solução de pigmentação. Métodos: Sessenta ligaduras foram selecionadas e divididas em doze grupos de acordo com a marca comercial utilizada e nas condições normal e distendida. Os grupos foram divididos em: Morelli transparente, TP Orthodontics transparente, American Orthodontics transparente, Unitek/3M transparente, American Orthodontics pérola e Unitek/3M pérola, separados quanto à condição normal e distendida, totalizando 5 ligaduras em cada condição. A avaliação das mudanças de coloração foi realizada por meio de fotografia digital e análise computadorizada usando o programa Adobe Photoshop. Foram realizadas fotografias digitais padronizadas nos tempos $\mathrm{T}_{0}$ - antes do processo de pigmentação, com as ligaduras em estado normal; e $\mathrm{T}_{1}$ - após o processo de pigmentação, que durou cinco dias. A solução de pigmentação utilizada foi composta por saliva artificial e por alimentos que possuem potencial de coloração. No tempo $\mathrm{T}_{1}$, as ligaduras se encontravam em estado distendido e em estado normal (sem distensão). Resultado: os resultados do presente estudo demonstraram que ligaduras elásticas estéticas são suscetíveis à pigmentação. Dentre as marcas comerciais avaliadas a TP Orthodontics e American Orthodontics transparente foram as mais estáveis. Já a Unitek/3M pérola demonstrou alterações estatisticamente significativas em todas as variáveis avaliadas. Conclusão: ligaduras elásticas estéticas são suscetíveis à pigmentação, não havendo diferença estatisticamente significativa entre o estado normal e o estado distendido, com exceção na marca TP Orthodontics. A marca Unitek/3M pérola demonstrou ser a que apresenta maior potencial para pigmentação.

Palavras-chave: Estética. Pigmentação. Fotografia. Ligadura.

${ }^{1}$ Specialist in Orthodontics and Facial Orthopedics, UFBA.

${ }^{2}$ Professor of the Specialization Course in Orthodontics and Facial Orthopedics, UFBA.

» The authors report no commercial, proprietary or financial interest in the products or companies described in this article.

\begin{abstract}
How to cite this article: Cavalcante JS, Castelluci e Barbosa M, Sobral MC. Evaluation of the susceptibility to pigmentation of orthodontic esthetic elastomeric ligatures. Dental Press J Orthod. 2013 Mar-Apr;18(2):20.el-8.
\end{abstract}

Submitted: August 11, 2009 - Revised and accepted: December 172010 Contact address: Janine Soares Cavalcante

Rua Eucalipto, 30 - Cond. J. do Horto - Gruta de Lourdes

CEP: 57052-890 - Maceió/Alagoas - Brazil

E-mail: janinescavalcante@yahoo.com.br 


\section{INTRODUCTION}

Over the years patients have developed an increasingly critical approach to their own esthetics and, as a result, an attractive appearance during treatment with fixed orthodontic appliances is in widespread demand among patients, especially adults. ${ }^{8}$ All this concern with esthetics during orthodontic treatment has fueled the use of esthetic brackets, wires and elastomeric ligatures.

Increased demand for an esthetically pleasing appearance during treatment with fixed appliances requires esthetic accessories, such as ligatures that match the color of esthetic brackets. These elastomeric products, or ligatures, feature certain advantages such as elastic memory, are easily installed, biocompatible, motivate patients during orthodontic treatment, and are comfortable, ${ }^{19,23}$ with decreased risk of damage to the oral mucosa. ${ }^{18,25}$

However, they have some disadvantages, such as changes in physical properties when exposed to moist environments, ${ }^{13,14}$ degradation in the amount of force released over time, poor seating of the archwire during application of torque or rotation correction. ${ }^{5,23} \mathrm{Com}-$ pared with steel ligatures, elastomeric ligatures involve hygiene-related issues since there is greater plaque accumulation around the bracket. ${ }^{18,23,25}$

Elastomeric ligatures can be manufactured with two types of materials: Latex or synthetic elastomers. Rubber or latex ligatures are obtained by vegetable extraction, ${ }^{18}$ whereas synthetic elastomers, also called plastics, are made from polyurethane materials derived from crude oil, coal and some vegetable alcohols. ${ }^{18,19,20}$

Resilience is one of the most convenient characteristics of latex rubbers, while their greatest limitation is the swelling and staining that occur as fluids and bacteria seep into the vacuum of the rubber matrix, ${ }^{25}$ which shortens their lifespan.

The basic repeated structure of the polymers that comprise polyurethane rubber impart to plastics a wide variety of physical properties. ${ }^{25}$ However, the exact product composition is held in secret by manufacturers $^{19,25}$ and the quality of these materials is dependent on the manufacturing process. ${ }^{22,23}$ Thus, ligature composition results from a combination of technology, technique refinement and quality of the raw materials used during manufacture. ${ }^{22,23}$

When exposed to the oral environment for a lengthy period of time these ligatures absorb water and saliva, which disrupts internal connections, thereby promoting permanent deformation. ${ }^{19}$ The physical properties and appearance of these materials may also be affected by exposure to mastication forces, and besides the absorption of fluids and saliva, the absorption of food pigments also occurs. ${ }^{2,18,25}$ According to Wong, ${ }^{25}$ elastomeric materials are prone to staining by some types of food.

Any efficient method for measuring color should be reliable, easy to use and allow outcome assessment. Given its usefulness, digital photography has established itself as a new method for measuring and analyzing color through computer programs. ${ }^{15,16}$ With the aid of the Adobe Photoshop, a color analysis software, degrees of image brightness $(\mathrm{R}, \mathrm{G}, \mathrm{B})$ can be evaluated using the Histogram tool. ${ }^{3,12,21}$

In seeking to ensure a long-lasting esthetic effect and assuming that these elastomers undergo staining when exposed to certain foods, it is important to assess susceptibility to staining of these materials by those foods. The aim of this study therefore, was to assess, in vitro, the susceptibility to staining of esthetic orthodontic elastomeric ligatures of two different types, i.e., (a) colorless/ clear and (b) pearl/obscure color, offered by different manufacturers.

\section{MATERIAL AND METHODS}

This is an experimental and longitudinal in vitro study. The total sample consisted of 40 colorless/ transparent (clear), and 20 pearl/obscure color elastomeric ligatures, all used in orthodontic procedures for ligating orthodontic archwires to brackets.

The clear elastomeric ligature brands used in the study were as follows: Morelli, TP Orthodontics, American Orthodontics and 3M/Unitek. The pearl color ligature brands were manufactured by American Orthodontics and 3M/Unitek. Ligatures were divided into twelve groups with five ligatures each, according to brand and unstretched or stretched condition. It should be noted that both clear and pearl color samples of the American Orthodontics brand, and clear and pearl of the $3 \mathrm{M} /$ Unitek brand were employed.

Digital photographs were used to evaluate ligature color. Photographs were taken with a digital camera (Canon EOS Rebel XT model, with 6.8 megapixel resolution and 12-bit color depth). Images were recorded in manual mode with the following settings: Speed 5 (0.2 seconds), diaphragm aperture 11-in, position (height) of the desktop camera stand at a distance of $36 \mathrm{~cm}$, 
ISO 100, no flash, auto mode with timer set to shoot after 10 seconds, image storage in RAW format. A 60 mm Canon EF-S, 1:2.8 macro, was used in an environment completely free from natural light, lighted only by an Portable Transparency Viewer 4050v (Visual Plus ${ }^{\circledR}$ ) negatoscope. The negatoscope was placed on a desktop camera stand (Atek) (Fig 1), and above it, the ligature was placed under the camera focus.

The camera was fixed to an arm on the camera stand and positioned perpendicular to the stand, and the focus-object distance was set at $9 \mathrm{~cm}$. Each ligature was placed on the camera stand so that the circumference of the ligature was superimposed on top of a reference point at the center of the viewfinder.

The images (Fig 2) were transferred to the computer using the File View Utility program, in RAW format, and thereafter converted and stored in 8-bit TIFF format. Subsequently, all the images were analyzed by the color management program built into Adobe Photoshop CS2, version 9.0. With the aid of this software, under a 100\% zoom, an area of $0.3 \mathrm{~cm}$ wide by $0.3 \mathrm{~cm}$ in height was determined on the circumference of the elastomeric ligature (Fig 3). The colors that were present in this area were evaluated with the Histogram function through levels of brightness (B), Red (R), Green (G), Blue (B) and RGB.

Color measurement using the RGB model is performed with the aid of values on a scale ranging from 0 to 255 , which provides the precise blend of a given color. These values ( 0 up to 255 ) also serve as a guide to adjust the image color and the tone levels either jointly (RGB) or separately, i.e., R, G and B. As the value comes near to 0 (zero), the image being analyzed turns darker. Similarly, the closer it gets to 255 , the lighter or whiter the image becomes. Thus, a given substance can be analyzed and perceived as being lighter or darker in relation to these values.

Before proceeding with the experiment, a repeatability test was performed on the photographs to determine the degree of reliability afforded by the methodology used in the experiment. To this end, four ligatures from different manufacturers were employed. Each ligature was photographed three times a day for eight days, totalizing 96 photographs. In the mean time, the ligatures were stored in the refrigerator to avoid compromising the final result of the test. This was accomplished based on the same initial assumptions of underpinning the experiment.

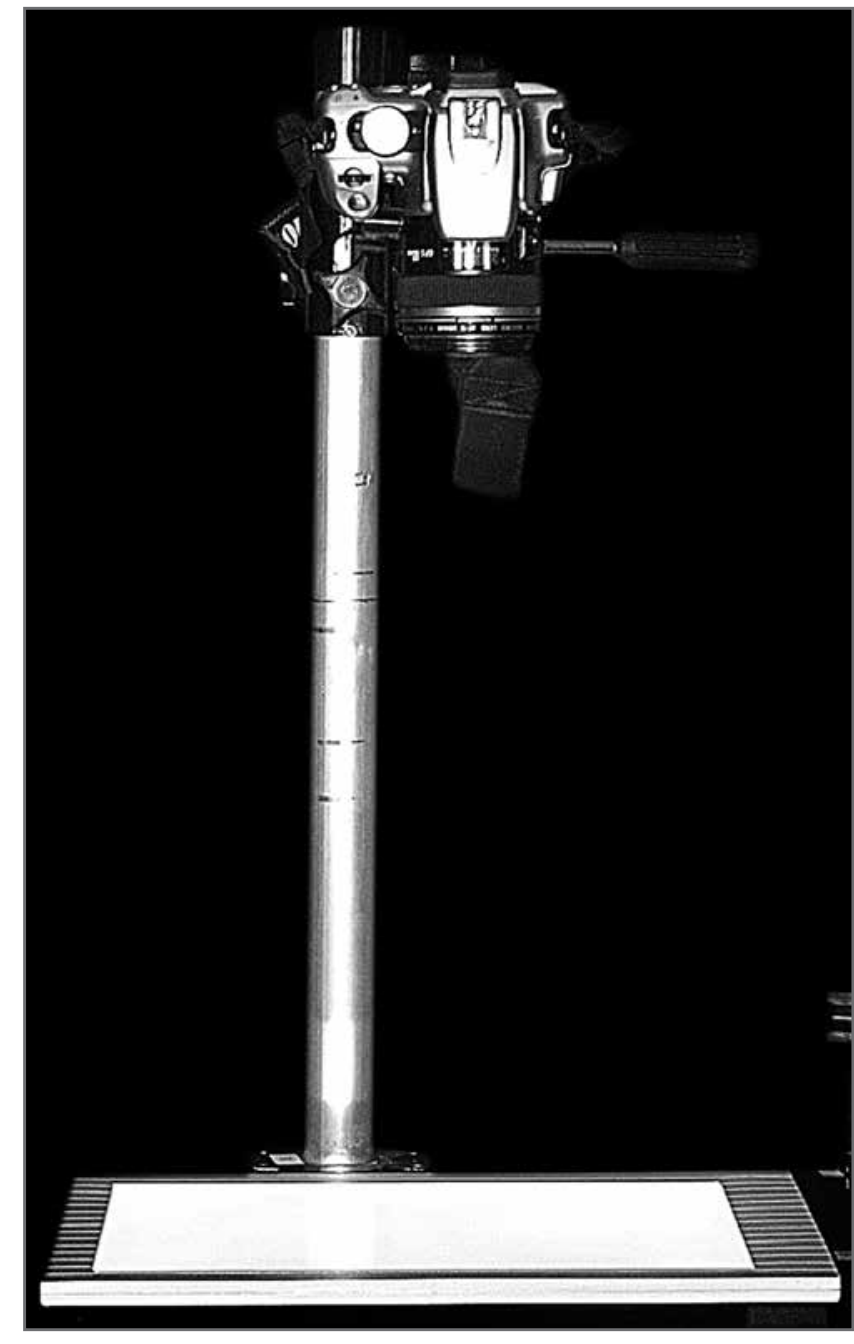

Figure 1 - Camera in position on the desktop camera stand.

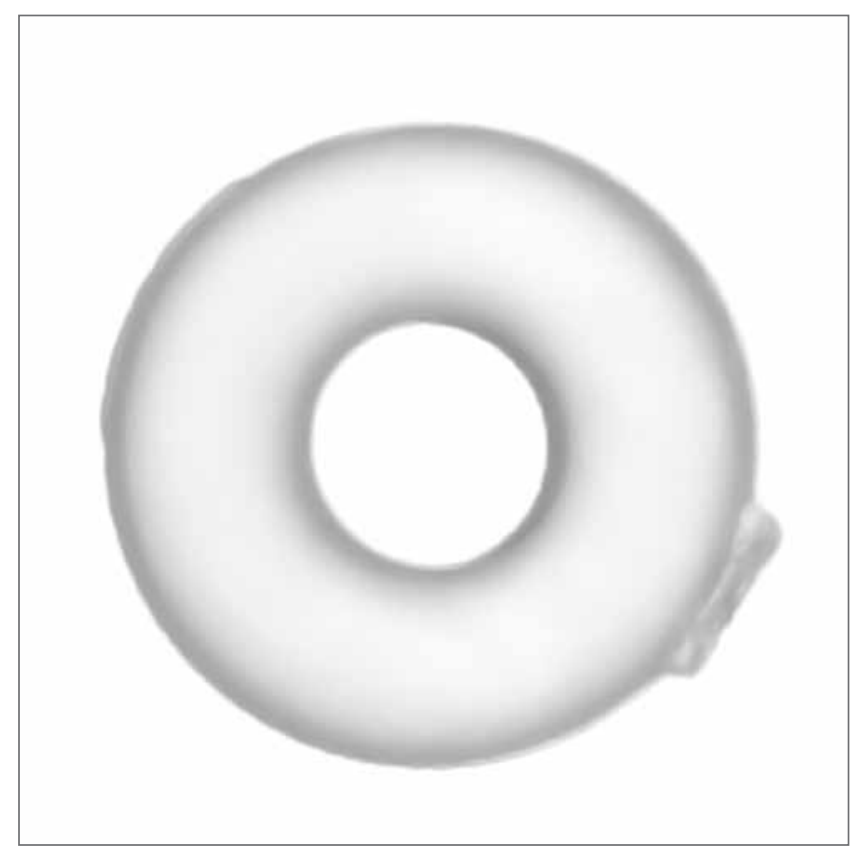

Figure 2 - Ligature prior to staining process. 


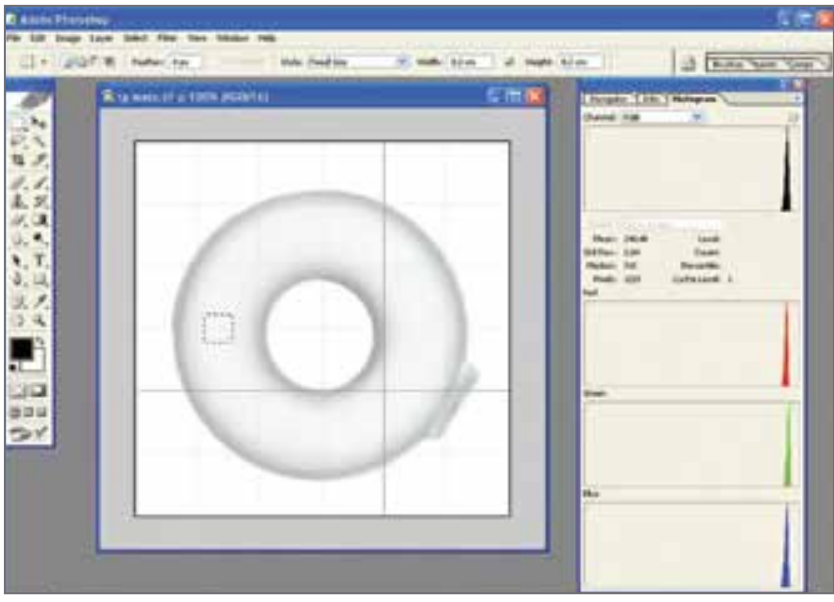

Figure 3 - Digital image rendered with Adobe Photoshop CS2 version 9.0.

Data from the repeatability test were statistically verified using analysis of variance (ANOVA) to disclose whether variability between the different measures would be statistically significant. After obtaining and testing the values, the accuracy of the method was validated and confirmed, so the experiment could be initiated.

Each elastomeric ligature was separated into individual containers that determined the group to which they belonged. The groups of ligatures to be stained in the unstretched and stretched groups were also separated. All ligatures were handled following manufacturer recommendations and using a dressing forceps.

Thirty ligatures (5 of each brand) were photographed. One photograph was taken of each unstretched ligature, totalizing 30 photographs at $\mathrm{T}_{0}$, i.e., prior to the staining process.

To test ligature susceptibility to staining, a solution comprising $250 \mathrm{ml}$ of coffee, $250 \mathrm{ml}$ of black tea, $250 \mathrm{ml}$ of red wine, $250 \mathrm{ml}$ of flat (fizzless) Coca-Cola, $250 \mathrm{ml}$ of a smoke roll infusion and $250 \mathrm{ml}$ of artificial saliva was prepared..$^{10}$ This solution was homogenized and stored in an oven (Biomatic brand) at $37^{\circ} \mathrm{C}$ for 48 hours.

All 60 ligatures divided into their groups were then immersed in a staining solution and placed in an oven at $37^{\circ} \mathrm{C}$ for 5 days. Thirty ligatures were immersed in their normal state (unstretched). The remaining 30 ligatures were stretched using a device that reproduced a degree of stretching that resembled that state of a ligature ligating a bracket (Fig 4) and then they were immediately immersed in the solution along with the device.

The ligatures were removed from the staining solution, the stretched ligatures were removed from the de-

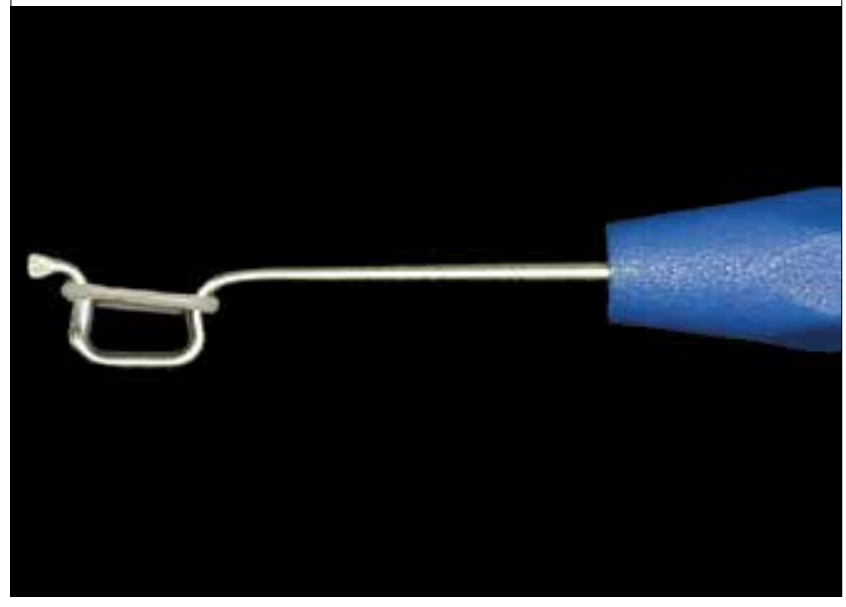

Figure 4 - Device used to stretch ligatures.

vice used to stretch them, all ligatures were then washed with distilled water for 1 minute, dried with compressed air and once again digitally photographed, totaling 60 photographs at $T_{1}$, i.e., after the staining process. Following, computerized assessment was performed with the aid of Adobe Photoshop CS2 version 9.0, under the same conditions described above.

\section{RESULTS}

After obtaining mean values for B, R, G, B and RGB for each group, ANOVA was performed to investigate whether the difference between variables was statistically significant between the groups. After ANOVA yielded positive results $(p=0.000)$, Student's $t$ test was performed to determine the difference between the means for $\mathrm{B}, \mathrm{R}$, $\mathrm{G}, \mathrm{B}$ and RGB in all groups. Both tests were performed at $\mathrm{T}_{0}$, before the staining process, and at $\mathrm{T}_{1}$, after the staining process with the unstretched and stretched ligatures.

The values found for each ligature brand at $T_{0}$ and $T_{1}$ can be seen in Tables 1 to 3 .

At $T_{0}$ a statistically significant difference in all variables, i.e., red, green, blue, brightness and RGB, was found between the ligatures. At $\mathrm{T}_{1}$, in the absence of stretching, a significant statistical difference was also found between the ligatures under all conditions. At $T_{1}$, in the presence of stretching, the result was similar to the unstretched group, with statistically significant differences between the groups.

Student's $t$ test was applied to all groups to evaluate color variation through absolute mean differences for RGB between $\mathrm{T}_{0}$ and $\mathrm{T}_{1}$, in unstretched and stretched ligatures (Figs 5 and 6). 
The values found indicate that all brands of ligatures were susceptible to staining. The ligatures manufactured by Morelli, American Orthodontics, 3M/Unitek, TP Orthodontics and American Orthodontics pearl color showed similar behavior regardless of being unstretched or stretched. Performance of the pearl ligatures manufactured by $3 \mathrm{M} /$ Unitek was notorious in the sense that they exhibited the largest amount of RGB variation, i.e., the most significant changes in color.

\section{DISCUSSION}

In order to analyze susceptibility to staining of esthetic ligatures - which enables a more pleasing cosmetic effect during treatment - all brands used in the experiment were evaluated with respect to brightness (B), Red (R), Green (G) Blue (B) and RGB through digital photography and computer analysis using Adobe Photoshop CS2 version 9.0. In examining the levels of $B, R, G, B$ and RGB found at $T_{0}, T P$

Table 1 - Means and standard deviations for red, green, blue, brightness and RGB values at $T_{0}$ by elastomeric ligature type.

\begin{tabular}{|c|c|c|c|c|c|}
\hline & Red & Green & Blue & Brightness & $\mathrm{RGB}$ \\
\hline & Mean \pm SD & Mean \pm SD & Mean \pm SD & Mean \pm SD & Mean \pm SD \\
\hline Morelli & $240.00 \pm 1.66$ & $242.18 \pm 1.49$ & $240.54 \pm 1.72$ & $241.34 \pm 1.56$ & $240.91 \pm 1.62$ \\
\hline American Orthodontics & $239.66 \pm 2.82$ & $241.84 \pm 2.53$ & $240.16 \pm 3.17$ & $240.96 \pm 2.65$ & $240.54 \pm 2.68$ \\
\hline Unitek & $222.34 \pm 1.57$ & $224.72 \pm 1.50$ & $220.34 \pm 1.87$ & $223.44 \pm 1.54$ & $222.45 \pm 1.61$ \\
\hline $\mathrm{TP}$ & $241.05 \pm 1.18$ & $243.24 \pm 1.00$ & $241.78 \pm 1.17$ & $242.42 \pm 1.07$ & $242.02 \pm 1.11$ \\
\hline American Orthodontics pearl & $160.93 \pm 1.32$ & $160.47 \pm 1.53$ & $136.15 \pm 2.45$ & $157.93 \pm 1.52$ & $152.56 \pm 1.60$ \\
\hline Unitek pearl & $169.94 \pm 1.32$ & $172.33 \pm 1.01$ & $165.99 \pm 1.00$ & $170.92 \pm 1.10$ & $169.42 \pm 1.10$ \\
\hline
\end{tabular}

Table 2 - Means and standard deviations for red, green, blue, brightness and RGB values at $T_{1}$ for unstretched ligatures by elastomeric ligature type.

\begin{tabular}{|c|c|c|c|c|c|}
\hline Eta & Red & Green & Blue & Brightness & $R G B$ \\
\hline & Mean \pm SD & Mean \pm SD & Mean \pm SD & Mean \pm SD & Mean \pm SD \\
\hline Morelli & $230.19 \pm 1.25$ & $233.47 \pm 1.04$ & $213.42 \pm 1.57$ & $230.29 \pm 0.98$ & $225.60 \pm 0.72$ \\
\hline American Orthodontics & $233.04 \pm 2.87$ & $236.58 \pm 2.74$ & $226.81 \pm 2.38$ & $234.45 \pm 2.74$ & $232.26 \pm 2.78$ \\
\hline Unitek & $211.29 \pm 3.59$ & $213.64 \pm 3.66$ & $193.78 \pm 5.16$ & $210.75 \pm 3.78$ & $206.24 \pm 4.08$ \\
\hline $\mathrm{TP}$ & $232.20 \pm 0.62$ & $235.40 \pm 0.59$ & $224.86 \pm 0.57$ & $233.28 \pm 0.59$ & $230.82 \pm 0.58$ \\
\hline American Orthodontics pearl & $151.12 \pm 3.37$ & $146.09 \pm 3.44$ & $103.48 \pm 3.12$ & $142.91 \pm 3.91$ & $133.42 \pm 3.31$ \\
\hline Unitek pearl & $139.92 \pm 1.83$ & $136.89 \pm 1.61$ & $108.43 \pm 1.34$ & $134.67 \pm 1.48$ & $128.42 \pm 1.35$ \\
\hline
\end{tabular}

Table 3 - Means and standard deviations for red, green, blue, brightness and RGB values at $\mathrm{T}_{1}$ for stretched ligatures by elastomeric ligature type.

\begin{tabular}{|c|c|c|c|c|c|}
\hline \multirow{2}{*}{ Elastomeric ligature } & Red & Green & Blue & Brightness & RGB \\
\hline & Mean \pm SD & Mean \pm SD & Mean \pm SD & Mean \pm SD & Mean \pm SD \\
\hline Morelli & $229.08 \pm 1.80$ & $231.63 \pm 1.55$ & $202.72 \pm 1.39$ & $227.69 \pm 1.39$ & $221.14 \pm 1.40$ \\
\hline American Orthodontics & $229.92 \pm 2.33$ & $233.31 \pm 2.26$ & $218.12 \pm 4.47$ & $230.62 \pm 2.38$ & $227.11 \pm 2.73$ \\
\hline Unitek & $210.21 \pm 1.54$ & $211.10 \pm 1.04$ & $186.95 \pm 1.62$ & $208.16 \pm 1.16$ & $202.75 \pm 1.23$ \\
\hline TP & $228.63 \pm 0.88$ & $231.54 \pm 0.71$ & $214.21 \pm 1.61$ & $228.77 \pm 0.81$ & $224.80 \pm 0.97$ \\
\hline American Orthodontics pearl & $150.55 \pm 3.52$ & $146.24 \pm 4.05$ & $103.83 \pm 4.51$ & $142.85 \pm 3.91$ & $133.43 \pm 3.98$ \\
\hline Unitek pearl & $140.08 \pm 2.53$ & $136.56 \pm 1.93$ & $101.42 \pm 3.55$ & $133.75 \pm 1.99$ & $126.02 \pm 2.18$ \\
\hline
\end{tabular}




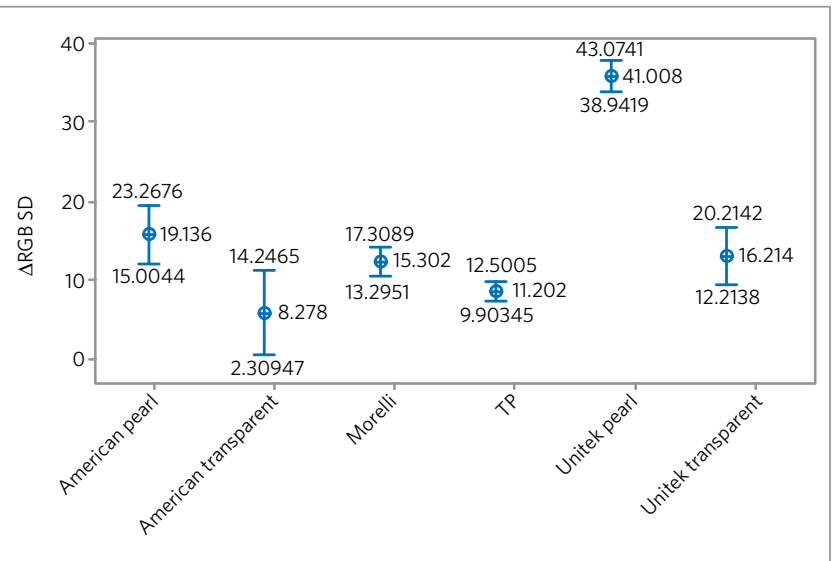

Figure 5 - Absolute difference ( $\triangle \mathrm{RGB}$ ) of RGB means for different brands of ligature at $T_{0}$ and $T_{1}$ in unstretched condition.

Orthodontics ligatures showed an increased risk for staining, followed by Morelli, American Orthodontics, 3M/Unitek, 3M/Unitek pearl color and American Orthodontics pearl color. The difference in proneness to staining among these different ligatures may reflect the different compositions of these products. Several authors confirm this assertion. ${ }^{19,22,23,25}$ It is possible to note that the lowest values were found for pearl/obscure color ligatures, indicating that the amount of pigment found in the color composition of these elastomers causes an increase in the final density of the material, thereby promoting changes in the values of the variables analyzed.

At $T_{1}$, with unstretched ligatures, mean values were lower compared to the values found at $\mathrm{T}_{0}$, demonstrating that staining occurred in these ligatures. American Orthodontics and TP Orthodontics ligatures exhibited the lowest susceptibility to staining on exposure to the staining solution. Morelli ranks next with values that are very close to the aforementioned American and TP Orthodontics ligatures, with the exception of the variable B (blue), in which Morelli's assessment was substantially below average, showing a statistically different performance $(p=0.002)$. In variables $R$ (red) and $G$ (green), American Orthodontics, Morelli and TP Orthodontics ligatures had a similar performance, with American Orthodontics pearl color and $3 \mathrm{M} /$ Unitek pearl color ligatures achieving lower values. Thus, according to the RGB color model, a decrease in the means analyzed indicates the presence of pigments in these ligatures.

At $\mathrm{T}_{1}$, with stretched ligatures, results were similar to those found in the unstretched sample, ANOVA $(p=0.000)$, where the mean values for American Orthodontics ligatures were the highest and closely matched

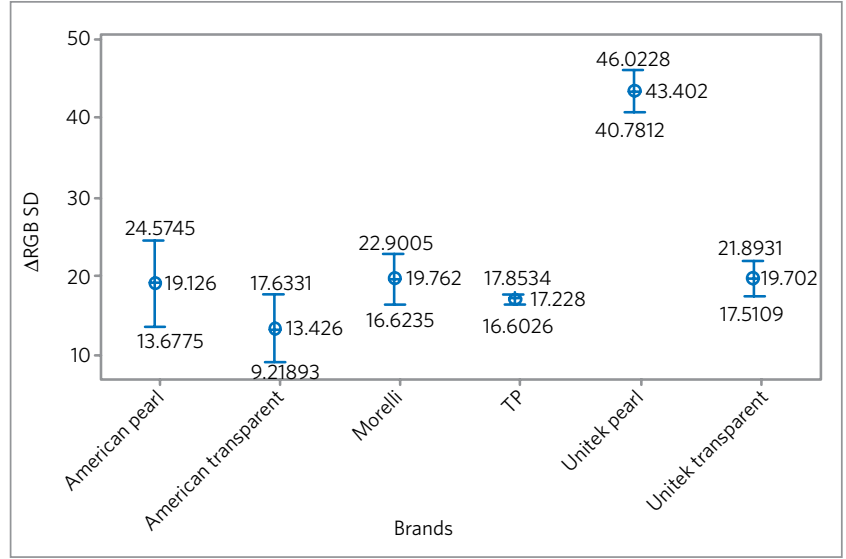

Figure 6 - Absolute difference $(\triangle R G B)$ of RGB means for different brands of ligature at $T_{0}$ and $T_{1}$ in stretched condition.

TP Orthodontics and Morelli values, with American Orthodontics pearl color and 3M/Unitek pearl color achieving the lowest values. These values demonstrate that no difference exists between ligatures in terms of being stretched or unstretched so that researchers in further studies can rest assured that this variable will have no bearing on the final values.

In assessing the variable brightness, a statistically significant variation was found at $\mathrm{T}_{0}$ and $\mathrm{T}_{1}$ in all brands. The lower values achieved by the pearl/obscure color ligatures at both $\mathrm{T}_{0}$ and $\mathrm{T}_{1}$ are worthy of note. According to the principle of optical fluorescence, an object has the ability to emit light with a wave length that is different from the source of the light falling upon it. ${ }^{25}$ Thus, when exposed to the light of a negatoscope, ligatures emit light. However, due to the fact that pearl/obscure color ligatures have a different structural composition from that of clear ligatures, they emit a smaller amount of light than those which do not have color pigments.

Regarding variable red (R), all ligatures changed their color during the experiment. The most stable brands displayed a similar performance at both $\mathrm{T}_{0}$ and $\mathrm{T}_{1}$, namely: TP Orthodontics and American Orthodontics. However, the biggest difference between $T_{0}$ and $T_{1}$ was found in the $3 \mathrm{M} /$ Unitek pearl color ligatures. In view of the fact that the solution components tend toward the color red, one can infer that staining occurred in all groups during the study, yielding statistically significant values. This finding was also posited by Libório ${ }^{27}$, who used the same staining solution to study susceptibility of esthetic brackets to staining and found changes in color in all ligature brands evaluated. 
Regarding the change of color to green $(G)$, there was no statistical difference between time $T_{0}$ and $T_{1}$ in all brands. The values found in each brand analyzed varied at both $\mathrm{T}_{0}$ and $\mathrm{T}_{1}$. Notorious among these, were the $3 \mathrm{M} /$ Unitek pearl color and American Orthodontics pearl color ligatures at $T_{1}$ in both unstretched and stretched condition. The values attained by these two manufacturers may indicate similarity in the composition of their ligatures.

As regards the variable blue (B), all brands analyzed exhibited final numerical values that were lower than baseline, which was an expected behavior in line with the behavior of other variables. Ligatures manufactured by American Orthodontics and TP Orthodontics displayed a similar performance. The worst performance of the blue color was displayed by $3 \mathrm{M} /$ Unitek, followed by $3 \mathrm{M} /$ Unitek pearl color, as in the other variables. The wide variation of blue, with a significant decrease in value, can be explained by the fact that red had shown only a slight decrease. According to Gomes, ${ }^{10}$ the components used in the staining solution tend toward red, and these two colors are at opposite ends of the light spectrum.

Since color perception and interpretation are subjective, ${ }^{11}$ one single numerical assessment of variables $\mathrm{B}, \mathrm{R}$, $G$ and $B$ may not be sufficient for adequate perception of the color changes undergone by each brand in this investigation. It is noteworthy that variation between times $\left(\mathrm{T}_{0}\right.$ and $\left.\mathrm{T}_{1}\right)$ is more important than final mean values, since one cannot disregard the original characteristics inherent in the material, which play a relevant part in the outcome. However, even if the same values are reached, the changes in color disclosed in the results may be masked when these ligatures are in the oral environment and form part of the tooth-bracket-ligature complex, where each element used separately is likely to influence the perception of changes in ligature pigmentation. Further studies are therefore suggested in order to determine the influence of ligature staining on smile esthetics.

As regards changes in color $(\triangle \mathrm{RGB})$ between $T_{0}$ and $\mathrm{T}_{1}$, the results were similar in both unstretched and stretched ligatures. 3M/Unitek pearl color ligatures showed greater tendency to staining. The other brands also underwent staining, but all fell within a range of lower values, similar to the delta values under the two conditions tested.

TP Orthodontics and American Orthodontics ligatures exhibited greater stability with similar perfor- mance, although TP Orthodontics ligatures were the only ones that revealed statistical differences in their susceptibility to staining under both unstretched and stretched conditions. This difference may be disputed given the fact that no colorimeter or spectrophotometer was used in the measurements, since these are standard instruments for measuring colors. ${ }^{7}$ Certain limitations were present in the material analyzed, such as the need to have a flat surface with minimum extent and thickness as to allow color measurement. ${ }^{4,24}$ Although some ligatures were evaluated because they had a polished surface, this surface was not flat. Moreover, the extent and thickness were not sufficient to yield a correct evaluation with these instruments. However, the method used in this study does not invalidate the results, since nowadays digital color assessment is a widely accepted method. ${ }^{16}$

It is vital that professionals learn about how esthetic ligatures tend to behave before using them, since factors such as specific colors, diet and length of time that the ligature remains in the oral environment, will likely influence the final esthetic appearance, often at the expense of frustrating the patient's expectation. Fraunhofer et al, ${ }^{9}$ grounded in findings obtained from an in vitro experiment argue that the in vivo behavior of elastomers may be different due to variables such as temperature changes in the oral environment, and masticatory forces.

The findings of this study pertain only to the susceptibility to staining of esthetic ligatures evaluated by a computer program. At what point these changes can be perceived on a daily basis and to what extent they can cause inconvenience to the patient could be the subject of further investigation.

\section{CONCLUSIONS}

The results show that the esthetic ligatures assessed are susceptible to staining, with no difference found between them as far as their condition during the pigmentation process, i.e., whether they were stretched or unstretched, except for the TP Orthodontics clear (colorless) ligatures, which absorbed more pigments upon stretching.

Despite their proneness to staining, TP Orthodontics and American Orthodontics colorless ligatures were more stable and less susceptible to color change. Conversely, there was marked susceptibility to staining in the $3 \mathrm{M} /$ Unitek pearl color ligatures. 


\section{REFERENCES}

1. Araujo FBC, Ursi WJS. Estudo da degradação da força gerada por elásticos ortodônticos sintéticos. Rev Dental Press Ortod Ortop Facial. 2006:11(6):52-61.

2. Beattie S, Monaghan P. An in vitro study simulating effects of daily diet and patient elastic band change compliance on orthodontic latex elastics. Angle Orthod. 2004;74(2):234-9.

3. Blatner D. Fraser B. Real World Adobe Photoshop CS. USA: Peach Press: 2004

4. Bolt RA, Bosch JJ, Coops JC. Influence of window size in smallwindow color measurements, particularly of teeth. Phys Med Biol. 1994;39(7):1133-42

5. Bortoly TG, Guerrero AP, Rached RN, Tanaka O, Guariza-Filho O, Rosa EA Sliding resistance with esthetic ligatures: An in-vitro study. Am J Orthod Dentofacial Orthop. 2008;133(3):340.e1-7.

6. Chimenti C, Franchi L, Di Giuseppe MG, Lucci M. Friction of orthodontic elastomeric ligatures with different dimensions. Angle Orthod 2005:75(3):421-5

7. Cho BH, Lim YK, Lee YK. Comparison of the color of natural teeth measured by a colorimeter and Shade Vision System. Dent Mater 2007:23(10):1307-12

8. Faltermeier A, Behr M, Müssig D. Esthetic brackets: The influence of filler level on color stability. Am J Orthod Dentofacial Orthop. 2007:132(1):5.e13-6.

9. von Fraunhofer JA, Coffelt MT, Orbell GM. The effects of artificial saliva and topical fluoride treatments on the degradation of the elastic properties of orthodontic chains. Angle Orthod. 1992;62(4):265-74

10. Gomes LO. Avaliação de alterações cromáticas do esmalte bovino submetido a procedimento de clareamento dental após descolagem de bráquetes ortodônticos [dissertação]. Salvador (BA): Universidade Federal da Bahia; 2005

11. Grey T. Foundations. In: Grey T. Color Confidence: the digita photographic guide to color management. San Francisco: Sybex London: 2004. p. 1-22

12. Halazonetis DJ. What does the histogram of an image show? Am J Orthod Dentofacial Orthod. 2004;125(2):220-2

13. Henriques JFC, Hayasaki SM, Henriques RP. Elásticos ortodônticos: como selecioná-los e utilizá-los de maneira eficaz. J Bras Ortodon Ortop Facial. $2003 ; 8(48): 471-5$
14. Huget EF, Patrick KS, Nunez LJ. Observations on the elastic behavior of a synthetic orthodontic elastomer. J Dent Res. 1990;69(2):496-501.

15. Joiner A. The bleaching of teeth: a review of the literature. J Dent 2006:34(7):412-9

16. Joiner A. Tooth color: a review of the literature. J Dent. 2003;32 Suppl 1:3-12

17. Kokich $V$. Esthetics and anterior tooth position: an orthodontic perspective. Part I: Crown Length. J Esthet Dent. 1993:5(1):19-23.

18. Loriato LB, Machado AW, Pacheco W. Considerações clínicas e biomecânicas de elásticos em ortodontia. Rev Clín Ortod Dental Press 2006:5(1):43-55

19. Martins MM, Mendes AM, Almeida MAO, Goldner MTA, Ramos VF, Guimarães SS. Estudo comparativo entre as diferentes cores de ligaduras elásticas. Rev Dental Press Ortod Ortop Facial. 2006:11(4):81-90.

20. Renick MR, Brantley WA, Beck FM, Vig KW, Webb CS. Studies of orthodontic elastomeric modules. Part 1: Glass transition temperatures for representative pigmented products in the as-received condition and after orthodontic use. Am J Orthod Dentofacial Orthop. 2004;126(3):337-43.

21. Scuri AE. Fundamentos da imagem digital. Disponível em URL: http:// www.tecgraf.pucrio.br/ortoledo/teaching/cg1/apostila\%20imagem\%20 digital. Acesso em: 28 Out. 2008.

22. Souza EV, Mendes AM, Almeida MAO, Quintão CCA. Percentual de degradação das forças liberadas por ligaduras elásticas. Rev Dental Press Ortod Ortop Facial. 2008:13(2):138-45.

23. Taloumis LJ, Smith TM, Hondrum SO, Lorton L. Force decay deformation of orthodontic elastomeric ligatures. Am J Orthod Dentofacial Orthop. 1997:111(1):1-11.

24. van der Burgt TP, ten Bosch JJ, Borsboom PC, Kortsmit WJ. A comparison of new and conventional methods for quantification of tooth color. J Prosthet Dent. 1990;63(2):155-62

25. Wong AK. Orthodontic elastic materials. Angle Orthod. 1976:46(2):196-204.

26. RGB. Wikipédia: a enciclopédia livre. Disponivel em: http://pt.wikipedia. org/wiki/RGB. Acesso em: 6 Maio 2009

27. Libório $\mathrm{AO}$. Avaliação da suscetibilidade à pigmentação de brackets estéticos utilizando a fotografia digital [dissertação]. Salvador (BA) Universidade Federal da Bahia, Faculdade de Odontologia; 2006. 